Oecologia, Vol. 66, No. 2, 1985, pp.168-177.

ISSN: (Print: 0029-8549) (Electronic: 1432-1939)

DOI: $10.1007 / \mathrm{BF} 00379851$

http://www.springerlink.com/

http://www.springerlink.com/content/j78n527lr2450762/fulltext.pdf

The original publication is available at www.springerlink.com

(C) Springer-Verlag

\title{
An analysis of the mechanisms governing species replacements in crayfish
}

\author{
Mark J. Butler IV ${ }^{1}$ and Roy A. Stein ${ }^{2}$ \\ ${ }^{1}$ Department of Biological Science, Florida State University. ${ }^{2}$ Department of Zoology, Ohio State University.
}

\begin{abstract}
Summary
We investigated mechanisms governing replacement of the native crayfish Orconectes sanborni by an invading crayfish, Orconectes rusticus. The two species had similar life histories, habitat preferences, and feeding patterns in allopatric and sympatric stream areas. Orconectes rusticus young-of-year (YOY) grew faster than $O$. sanborni YOY in the field. Adult $O$. rusticus were larger and, hence, dominant over adult $O$. sanborni; YOY were non-aggressive. In laboratory experiments, adult crayfish (about $28 \mathrm{~mm}$ carapace length or larger) were not susceptable to predation by largemouth bass (Micropterus salmoides, $30 \mathrm{~cm}$ total length) and did not alter shelter use when fish were present. Orconectes rusticus YOY were less susceptible to predation than $O$. sanborni YOY. Orconectes rusticus YOY reduced their vulnerability to largemouth bass by occupying shelters more often than YOY $O$. sanborni. In mixed-species mate-selection experiments, male $O$. rusticus and male $O$. sanborni preferentially mated with $O$. rusticus females. Inappropriate mate selection in sympatry may have caused the $90 \%$ reduction in recruitment for both species in 1982. Orconectes rusticus probably maintains greater population growth than $O$. sanborni, because (1) more gravid $O$. rusticus females occurred in sympatry, (2) O. rusticus produced more young than $O$. sanborni, and (3) $O$. rusticus young grew faster. Reproductive interference, acting synergistically with differences in aggressive dominance and young-of-year susceptibility to predation, appears to serve as the major mechanisms regulating replacement of $O$. sanborni by $O$. rusticus in Ohio streams.
\end{abstract}

Species introductions can elicit drastic changes in community structure (Laycock 1966; Courtenay and Robins 1973; Courtenay 1978; Zaret and Paine 1973; Smith and Tibbies 1980), but the underlying mechanisms controlling community changes are often not understood (see A Round Table on Research in Ecology and Evolutionary Biology. (1983). The American Naturalist, vol. 122). Monopolization of resources by competitively dominant, non-native species can promote replacement of native species, thus altering community structure and possibly stability (Pianka 1976; Diamond 1978; Tilman 1982). However, equally plausible hypotheses describing species replacements can be generated assuming autecological differences in native and non-native species' susceptibility and response to predation (Commins and Hassell 1976; Caswell 1978), parasitism (Freeland 1983), and stochastic processes (Wiens 1977; Connor and Simberloff 1979; Chesson and Warner 1981, Glasser 1982).

Range expansion by several species of crayfish, commensurate with replacement of the local species, is a relatively common phenomenon (Schwartz et al. 1963; Bouchard 1978; Smith 1979a). One species, O. rusticus (a crayfish endemic to Illinois, Indiana, and western Ohio), has been especially successful in extirpating native species in Wisconsin (Capelli 1982; Capelli and Magnuson 1983), New England (Smith 1981a); Canada (Berill 1978), and Ohio (Turner 1926; Jezernac 1967). In Ohio, O. rusticus is replacing O. sanborni in streams and rivers in the eastcentral and southern sections of the state. Historically, the western limited of $O$. sanborni's range extended to central and west-central Ohio, but range expansion by $O$. rusticus has resulted in 
extirpation of $O$. sanborni in those areas (Turner 1926). The two species are currently sympatric in the Licking River system in east-central Ohio, where we worked.

Circumstantial evidence (Capelli 1982; Butler personal observation) suggests that fishermen have introduced $O$. rusticus into many areas, accelerating range expansion. However, factors controlling crayfish replacements have not been rigorously tested (Capelli 1982). Habitat perturbation, favoring colonization by an invading, tolerant species is an unlikely cause of crayfish replacements, considering the range of habitat types and quality (high latitude oligotrophic lakes and streams to eutrophic midwestern ponds and rivers) over which replacements occur and the similarities in crayfish ecological tolerances (Bovbjerg 1970). Competitive exclusion has been invoked to explain species replacements (Bovbjerg 1970; Capelli 1982; Capelli and Munjal 1983; Capelli and Magnuson 1983), but evidence supporting these hypotheses is far from compelling and alternative hypotheses have not been tested.

Agonistic behavior can influence species overlap such that subordinate species become restricted to suboptimal habitats or diets (Hixon 1980; Berglund 1982). Because crayfish are non-territorial (Merkle 1969; Momot and Gowing 1972), yet aggressive (Bovbjerg 1953; Heckenlively 1970), they rely on agonism to procure food, shelter, and mates (Stein 1975; Bertness 1981). Thus, dominance could be critical in determining foraging and reproductive success of sympatric crayfish. If size determines dominance, then the larger species, O. rusticus, should dominate interspecific encounters with $O$. sanborni. We tested whether aggressive dominance in young-of-year and adult $O$. rusticus and $O$. sanborni was size- or speciesdependent.

Crayfish of various life stages differ in their feeding habits; males and juveniles are more carnivorous than females and adults, respectively (Lorman 1975, 1980; Lorman and Magnuson 1978). Crayfish are generally opportunistic omnivores and demonstrate considerable interspecific diet overlap (Lorman and Magnuson 1978; Momot et al. 1978). Capelli and Hamilton (1984) suggested that competition for food might cause species replacements in oligotrophic lakes. However, no quantitative data describing food availability are available. If seasonal variation in food abundance occurs in streams, crayfish are probably most affected in late summer-early fall (before leaf fall), when water temperatures and crayfish densities are high. To evaluate the likelihood of food competition between crayfish, we compared diel food consumptions of the two species at allopatric and sympatric field sites in October 1982.

Given that competition for habitat occurs in some aquatic animals (Werner 1977; Grossman 1980; Larson 1980; Berglund 1982), do crayfish compete for space? Crayfish often select similar habitat types (Bovbjerg 1970; Caine 1978); however, Hazlett et al. (1979) found that suitable crayfish habitats were abundant and, thus, not a source of competition. Their conclusions are, as they concede, tentative because of the short duration of their experiments and the absence of controls. At present, no consensus or definitive study on the availability of suitable habitat for crayfish exists. To assess the possibility of habitat competition, we compared the habitat selection of $O$. rusticus and $O$. sanborni in allopatric and sympatric field sites.

As crayfish size or shelter use increases, predation by fish decreases (Stein and Magnuson 1976; Stein 1977; Medvick 1980). Stein and Magnuson (1976) and Stein (1977) found that certain crayfish life stages (i.e., juveniles, small adults, recent molts) modified their behavior and distribution to reduce their susceptibility to fish predators; relatively invulnerable, large crayfish altered their behavior only slightly. Young-of-year crayfish are particularly susceptible to predation, yet must balance predation risk with foraging benefits. Thus, differences between young-of-year assessment of, and response to, predation risk could prompt 
differential growth or mortality between species. In sympatry, the effective use of shelter may be complicated by interspecific similarities in habitat use and intraspecific interactions. To document the effects of fish predation on shelter use and mortality, we conducted a series of experiments on adult and YOY crayfish recording shelter use and mortality as a function of congener and predator presence.

Reproductive interference is a plausible species replacement mechanism, especially in indiscriminantly mating species like crayfish. Crayfish often mate interspecifically, though the success of those matings is probably low (Capelli and Capelli 1980; Smith 1981a, Butler personal observation). Intraspecific genetic and morphological variance in crayfish is often as high as interspecific variance (Smith 1979b, 1981b; Brown 1981). Hybridization seems likely. Capelli and Capelli (1980) present convincing morphological evidence for hybridization between $O$. rusticus and O. propinquus. Smith (1981b) suggests that hybrids might be sterile because of morphological aberrations in hybrid-male copulatory structures. Smith (1981a) also found apparent $O$. rusticus-O virilis hybrids in a sympatric stream area in southern New England. Two years later he found neither hybrids nor $O$. virilis, only $O$. rusticus, demonstrating the transient state of many sympatric areas and the inviability of $O$. rusticus-O . virilis hybrids. We combined experiments with field verification of reproductive success to test whether reproductive interference contributes to the replacement of $O$. sanborni by $O$. rusticus.

The Ohio O. rusticus-O. sanborni system is well suited for studies of interspecific interactions, because sympatric areas are recent, interactions are current, and the outcome of the interactions (e.g. replacement of $O$. sanborni) is known (see Connell 1980). Using laboratory experiments and field verification, we evaluated an array of mechanisms that might contribute to crayfish replacements. Focusing on the replacement of Orconectes sanborni by O. rusticus, we examined the species' (1) dominance relationships, (2) food consumption, (3) habitat selection, (4) shelter use and predation susceptibilities, and (5) reproductive success in allopatric and sympatric associations.

\section{General methods}

We sampled along a 5-km section of North Fork Creek, Licking River, a perennial second-order stream (elevation 1,160 m) draining an agricultural watershed in northern Licking and southern Knox counties, Ohio. North Fork averages $5 \mathrm{~m}$ in width and ranges in depth from $10-15 \mathrm{~cm}$ in riffles to $30-150 \mathrm{~cm}$ in pools. In this stream, we sampled a downstream O. rusticusonly site, an upstream $O$. sanborni-only site, and, between these, an $O$. rusticus-O. sanborni site; these sites were 1-2 km apart and clearly allopatric or sympatric. Crayfish were collected once a month in April, May, October, and November, and twice a month during June through September 1981-1982 using seines, hand nets, and a modified 1- $\mathrm{m}^{2}$ quadrat sampler. At each site about $100 \mathrm{~m}$ of stream were sampled, encompassing several riffle-pool complexes. Crayfish species, sex, life stage, and carapace length $(\mathrm{Cl}=$ anterior tip of rostrum to posterior dorsal edge of carapace) were recorded.

Laboratory animals were held in $120-1$ aquaria at $20-24^{\circ} \mathrm{C}$ and a constant photoperiod of $14 \mathrm{~h} \mathrm{~L}: 10 \mathrm{~h}$ D with slow-on, slow-off timers. Crayfish were fed beef heart, commercial fish food, and lettuce. 


\section{Life histories}

Data from museum collections (Museum of Zoology, The Ohio State University) and various field studies (Prins 1968; St. John 1970; Fielder 1972; Lorman 1980) suggest that $O$. rusticus and $O$. sanborni are synchronous in life history events such as mating, molting, and egg hatching but vary with geographic location and year.

In our samples, young-of-year (YOY) became independent in June or early July after a 12 week brooding period. At release, YOY were 4-7 mm CL and molted to 9-18 $\mathrm{mm}$ by October. Little growth occurred during winter; juveniles became sexually mature at about $20 \mathrm{~mm}$. Orconectes rusticus YOY grew faster than O. sanborni YOY $(P=0.09$ in laboratory, $P=0.01$ in field, ANCOVA test of homogeneity of slopes; Butler 1983) and were larger in October because of the nearly synchronous YOY emergence of the two species. Adult $O$. rusticus were larger than adults of $O$. sanborni $(P<0.01, t$-test) in allopatry and in sympatry. Adult males molted twice a year (early spring; late summer) and females once (early summer). Mating occurred primarily during August through early October when males were in breeding form (Form I; nonbreeding Form II). Following copulation, females retained sperm over winter, and eggs were extruded, attached to the ventral surface of the abdomen, and externally fertilized during March through April. Females brooded eggs and young for about 1 month

\section{Methods}

Dominance relationships - Two treatments were run. In treatment one, individuals were matched as to carapace $( \pm 5 \mathrm{~mm})$ and chela $( \pm 3 \mathrm{~mm})$ length. In treatment two, individuals were unequal in size: $>5 \mathrm{~mm}$ carapace length difference $(x=6.5 \mathrm{~mm})$ and $>3 \mathrm{~mm}$ chela length difference $(x=3.3 \mathrm{~mm})$. Data from sympatric field collections revealed that adult $O$. rusticus were on average $6 \mathrm{~mm}$ carapace length and $3 \mathrm{~mm}$ chela length larger than $O$. sanborni. Sexes were tested separately. In similar experiments with YOY crayfish, size differences were based solely on carapace length. Young-of-year were of equal size $( \pm 3 \mathrm{~mm})$ in treatment one and of unequal size (> $3 \mathrm{~mm}$ difference) in treatment two. We did not distinguish between males and females in these experiments.

Heterospecific pairs were placed in 10-liter aquaria (1-liter in YOY experiments), allowed to adjust for $2 \mathrm{~min}$, then observed until five interactions were recorded. We recorded threat, strike, fight, or avoidance following Bovbjerg's (1953) classification. Dominance and subordinance were determined from a comparison of agonistic and submissive behaviors; the dominant was the one that exhibited more agonistic behaviors. Typically, dominance was established within the first few min of a trial.

Food consumption - Crayfish were collected from allopatric and sympatric sites at 0600 and $2000 \mathrm{~h}$ on October 20 and 22, 1982, immediately placed on ice, then frozen in the laboratory. Crayfish were later thawed, measured, and sexed. Stomach contents were removed, and the body and the stomach contents were dried at $80^{\circ} \mathrm{C}$ for $48 \mathrm{~h}$ and weighed separately (nearest $\mathrm{mg}$ ). As did Lorman (1975), we found that the mass of stomach contents did not vary between sexes or among collection times $(P>0.05$, t-test, log transformed data). Hence, we grouped these data. To permit comparisons of stomach fullness across crayfish sizes, we calculated proportion fullness as described by Lorman (1975). Proportion fullness $(P)$ was calculated, where 


$$
\begin{aligned}
& \mathrm{P}= \\
& \mathrm{S}_{\max } \text { (estimated maximum dry mass of stomach contents) }
\end{aligned}
$$

To calculate $S_{\max }$, we plotted log dry weight of stomach contents (mg) against carapace length (mm) for each species and site (Butler 1983). Regressions representing $S_{\text {max }}$ were derived using only the maximum stomach content weights from each 4-mm carapace length class. Size did not influence stomach fullness for either species at any site $(\mathrm{P}>0.05$, ANOVA, arc sin transformed data); thus data were grouped across size classes.

Habitat selection - Densities of YOY and adult crayfish were estimated in three stream habitats: streambank, pool, and riffle. Streambanks are shallow $(<15 \mathrm{~cm})$ stream areas with low current velocities bordering the stream edges or the edges of islands. Pools and riffles are predominantly "non-edge" habitats; pools are relatively deep ( $>20 \mathrm{~cm}$ ) and have low current velocities, whereas riffles are of intermediate depth $(10-30 \mathrm{~cm})$ and high current velocities. Allopatric and sympatric sites were sampled once a month during June through October 1982; YOY were collected during August through October. A $1-\mathrm{m}^{2}$ modified quadrat sampler (Butler 1983) was tossed nine times along a 50-100 m section of stream (three samples per habitat at each of three stream sites). Within each quadrat, we measured water depth and visually estimated percent cover and mean size of cover. Cover was defined as rocks, leaves, and debris $>50 \mathrm{~cm}$ in area. Once habitat parameters were recorded, substrate within the quadrat was removed to a depth of $10 \mathrm{~cm}$ and all crayfish removed, measured, and identified. Substrate was then replaced and crayfish released.

To quantify habitat availability, we constructed maps of the three field sites and quantified the proportion of each habitat type at each site. To evaluate habitat selection, we used a method developed by Frank (1983) that determines habitat preference based on pairwise comparisons of relative usage. One-way ANOVAs were used to test for differences in percent cover (arcsin transformed data), mean cover size, and water depth within habitat type and among the three sites. Because sample sizes were small for each habitat per sample date, data were grouped across sampling dates for analysis.

Shelter use and predation susceptability - For information on shelter use in the absence of both congeners and predators, we placed four adult male crayfish (mean CL: O. rusticus $=28.5$ $\mathrm{mm}$, O. sanborni $=28.2 \mathrm{~mm}$ ) in 120-liter aquaria and allowed them to acclimate for 8-12 $\mathrm{h}$. Each aquarium was divided horizontally by a removable screen partition and contained four shelters (10-cm lengths of 6-cm polyvinylchloride pipe). Screen partitions prevented the fish predators from preying on crayfish but did not hinder visual or olfactory detection by predator or prey. Only one crayfish could occupy a shelter at a time. Observations on the number of crayfish occupying shelters were taken over 3 days at 0800, 1200, 1600, 2000, and $2200 \mathrm{~h}$. Eight replicates per species were run.

In treatment one, we monitored crayfish shelter use in the absence of a predator. To document shelter use in the presence of a non-feeding predator (treatment two), we added a largemouth bass (Micropterus salmoides, about $30 \mathrm{~cm}$ total length), satiated $24 \mathrm{~h}$ before the experiment, to the top aquarium compartment. Bass were added to aquaria in the dark, $10 \mathrm{~h}$ 
before the first observation at 0800 . Following the first two treatments, partitions were removed at 2200 on experimental day 6 and crayfish shelter use recorded. Thus, shelter use by each species and susceptibility to predation in the absence of congeners was determined.

Competition for shelter as a function of predator pressure was determined using essentially the same experimental design as in single-species experiments. However, in these experiments, four crayfish of each species (eight crayfish total) were placed together in aquaria with four shelters; shelter was therefore limited.

Similar experiments were conducted using YOY crayfish (mean CL: O. rusticus $=14.0$ $\mathrm{mm}, O$. sanborni $=12.5 \mathrm{~mm})$, except 5 - $\mathrm{cm}$ shelters $(2 \mathrm{~cm}$ diameter $)$ were used in place of the large shelters. Eight replicates per species were run.

For analysis, daylight observations $(0800,1200,1600)$, like night observations (2000 and $2200 \mathrm{~h}$ ), were grouped across the three experimental days ( $\mathrm{P}>0.05$ for all tests, ANOVA randomized complete block design). Using contingency tables, we compared numbers of crayfish using shelters in two ways: (1) between species within and among treatments and (2) between single-species and mixed-species experiments.

Mate selection - To estimate mating success in sympatry, we created mixed-species populations in the laboratory and observed matings. In mixed-species tanks we placed two males and two females of each species together in 120 -liter aquaria (density about $25 / \mathrm{m}^{2}$ ). Differences in size were similar to those found in the field (mean CL: $O$. rusticus males $=29.3 \mathrm{~mm}, O$. rusticus females $=24.3 \mathrm{~mm} O$. sanborni males $=26.7 \mathrm{~mm}, O$. sanborni females $=21.4 \mathrm{~mm}$ ). At hourly intervals from 0800 to $2200 \mathrm{~h}$ we recorded the numbers of inter- and intraspecific matings for 2 days. Twenty replicates were completed. Because crayfish matings typically last about $1 \mathrm{~h}$ (Capelli and Mclntire 1983) and most crayfish mate during the day (M.J. Butler, personal observation), it is unlikely that many matings were missed.

Reproductive success - To estimate reproductive success in the field, we collected gravid females from allopatric and sympatric sites in May 1982. Ventral and lateral views of the females' egg masses were photographed and the number of eggs per female estimated. Three females of each species from each site were sacrificed and direct egg counts made for comparison with visual estimates. Visual estimates differed from actual counts by less than $10 \%$, so no corrections were made in the estimates. The remaining females were separated and reared in the laboratory until eggs hatched. Young were counted at independence. 
Table 1. Results of adult (> $20 \mathrm{~mm} \mathrm{CL}$ ) and YOY (<20 mm CL) O. rusticus-O. sanborni aggressive dominance experiments. Values different from random (i.e., 50\% dominance) are designated by asterisks $(* *, \mathrm{P}<0.01$, chisquare test). 118 pairs of adult crayfish were tested. 72 pairs of YOY crayfish were tested, but only data from 29 pairs where aggression occurred were used in the analysis

\begin{tabular}{|c|c|c|c|}
\hline Treatment & $\begin{array}{l}\text { Number } \\
\text { of pairs } \\
\text { tested }\end{array}$ & $\begin{array}{l}\text { O. rusticus } \\
\text { dominant }\end{array}$ & $\begin{array}{l}\text { O. sanborn } \\
\text { dominant }\end{array}$ \\
\hline \multicolumn{4}{|l|}{ Adults } \\
\hline $\begin{array}{l}\text { O. rusticus larger } \\
\text { carapace }\end{array}$ & 68 & $77 \%$ & $23 \% * *$ \\
\hline $\begin{array}{l}\text { O. sanborni larger } \\
\text { carapace }\end{array}$ & 33 & $27 \%$ & $73 \% * *$ \\
\hline O. rusticus larger chela & 69 & $80 \%$ & $20 \% * *$ \\
\hline O. sanborni larger chela & 37 & $16 \%$ & $84 \% * *$ \\
\hline equal carapace & 12 & $41 \%$ & $59 \%$ \\
\hline equal chela & 12 & $46 \%$ & $54 \%$ \\
\hline \multicolumn{4}{|l|}{ Young-of-year } \\
\hline $\begin{array}{l}\text { O. rusticus larger } \\
\text { carapace }\end{array}$ & 15 & $67 \%$ & $33 \%$ \\
\hline $\begin{array}{l}\text { O. sanborni larger } \\
\text { carapace }\end{array}$ & 6 & $50 \%$ & $50 \%$ \\
\hline equal carapace & 8 & $0 \%$ & $100 \%$ \\
\hline
\end{tabular}

\section{Results and discussion}

Dominance relationships - Dominance in adult $O$. rusticus and $O$. sanborni was apparently governed by size (Table 1). If an individual was larger in carapace or chela length, it was usually dominant. When crayfish were of similar size, neither species dominanted. In similar experiments with $O$. rusticus, $O$. virilis, and $O$. propinquus (a species closely related to $O$. sanborni), Munjal (1980) found that $O$. rusticus was dominant over $O$. virilis but not over $O$. propinquus. Although $O$. rusticus was not inherently more aggressive than $O$. sanborni in our experiments, it was larger than $O$. sanborni in North Fork Creek and thus should dominate in this stream.

Young-of-year were aggressively active in only $40 \%$ (versus $100 \%$ for adults) of 72 trials (Table 1). In trials with aggression, the frequency of interaction was considerably lower than that for adults (0.25 versus 1.0 interactions/ min). Differences in species' dominance occurred only with similarly sized individuals; O. sanborni dominated O. rusticus (Table 1). Orconectes sanborni were not dominant when larger. Considering the lack of aggressiveness in YOY and the small sample size, these differences should be viewed with caution. Medvick (1979) found that YOY O. rusticus aggressively dominated YOY O. virilis and O. propinquus, regardless of size. She did not compare adult and YOY aggressiveness or report frequency of YOY interactions, which leaves unanswered the question of the relative importance of YOY aggression. Given that crayfish achieve 50-60\% of their ultimate size during their first summer's growth and YOY field densities often exceed 100 individuals $/ \mathrm{m}^{2}$ (H.H. Hobbs, III, personal communication), YOY 
should feed, not fight. Aggression would be useful to YOY only when (and if) important resources are limiting. Capelli and Hamilton (1984), in a series of laboratory experiments, found that shelter availability influenced aggressive activity in adult male $O$. rusticus more than food availability. Unfortunately, no such experiments have been conducted with YOY crayfish, and nothing is known about food and shelter availabilities in the field.

In summary, aggressive dominance was clearly size-dependent in adults, favoring $O$. rusticus; YOY were not aggressive. Benefits of dominance are obvious, particularly in situations where some critical resource is limited. However, even in systems where resources are abundant, aggressive encounters, favoring one species, can subject species to different selective forces (e.g., a situation where a predator approaches and two individuals must compete for a nearby shelter). Depending on the circumstances, these kinds of interactions may result in increased foraging costs or mortality for subordinate individuals and might thus contribute to species replacements.

Food consumption - In allopatric locations stomach fullness was similar for the two species $(P>0.05$, t-test, arcsin-transformed data). Mean stomach fullness for $O$. sanborni was $32 \%$ versus $39 \%$ for $O$. rusticus. In sympatry, O. rusticus consumed more food (mean stomach fullness $=48 \%)$ than did O. sanborni $(36 \%)(P=0.01 ;$ Fig. 1$)$. Because stomachs of both species contained more food in sympatry than in allopatry, interspecific interactions and/or site-specific resource differences were unimportant. Based on volumetric comparisons of food consumption

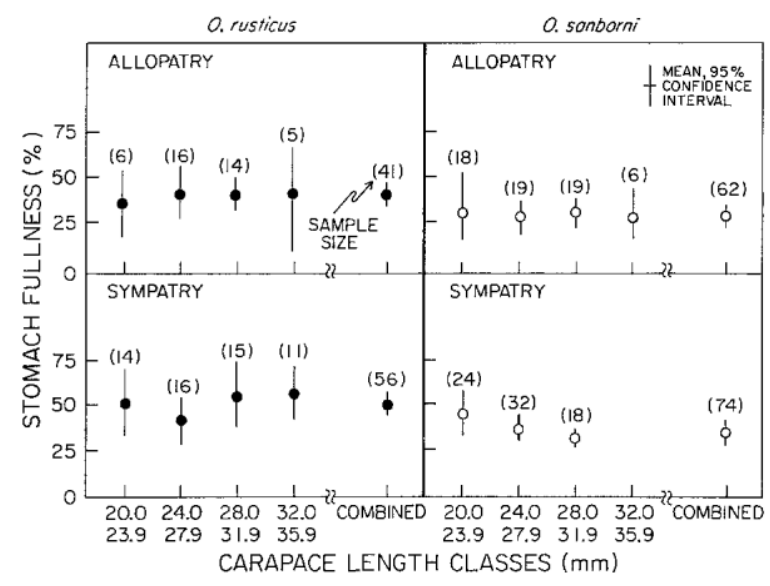

Fig. 1. Percent stomach fullness for adult O. rusticus and O. sanborni from allopatric and sympatric sites in North Fork Creek, Licking County, Ohio, in October 1982; Means and 95\% confidence intervals were plotted for each 4 $\mathrm{mm}$ length class and combined length classes

(which assume food items are of equivalent energetic and nutritional value), food resources appeared sufficiently abundant in October to preclude exploitative competition. Were food supplies as abundant during summer? Lorman (1975) quantified food consumption by $O$. rusticus in northern Wisconsin lakes. Mean stomach fullness declined slightly during June (37\%) through October (33\%) and November (28\%). If crayfish food consumption in June in Wisconsin is indicative of that of Ohio (as it is in October - mean percent stomach fullness: Wisconsin 33\%, Ohio 39\%), then food resources in Ohio might also be as abundant in June as in October. 
Bovbjerg (1970); studied the replacement of O. immunis by O. virilis, and compared stomach fullness and gut contents of the species in sympatry. Based on a single sample $(N=103$ crayfish), he also concluded that competition for food was of little or no importance in the interaction.

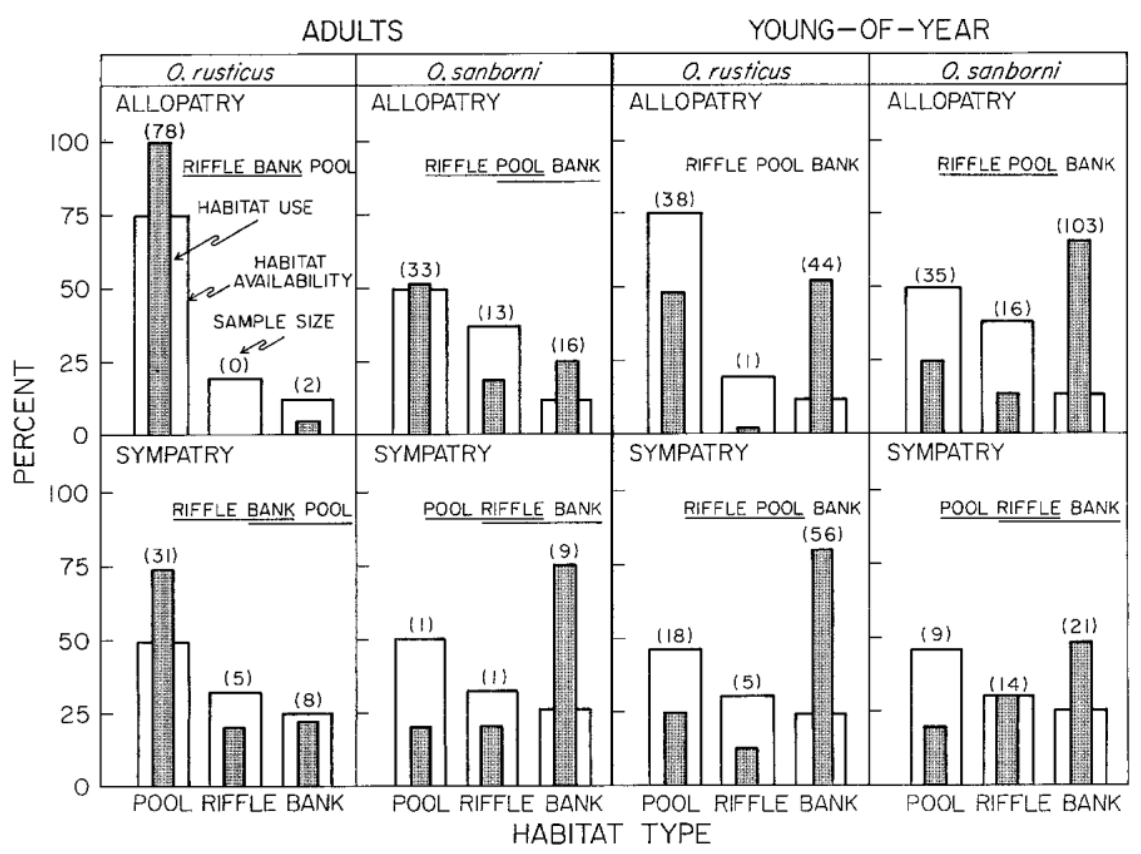

Fig. 2. Percent habitat use and availability for adult and young-of-year $O$. rusticus and $O$. sanborni in allopatric and sympatric field sites in North Fork Creek, Licking County, Ohio. Results of Frank's (1983) pairwise comparison test for habitat selection are summarized in each panel; values not different $(P>0.05)$ from each other are underlined. Habitat preference increases from left to right in these summaries. Sample sizes indicate total numbers of crayfish collected in that habitat over the 3-5 month (adult, young-of-year, respectively) sampling period

Considering the generalistic feeding habits of crayfish (Lorman 1975; Lorman and Magnuson 1978) and the lack of evidence for food limitation, it is unlikely that crayfish experience frequent "resource bottlenecks". Food in productive lotic systems (allochthonous and autochthonous debris, macrophytes, algae, benthic invertebrates and fish) is a diverse and rapidly renewable resource that may consitute an abundant resource for trophic generalists like crayfish. Though all documented analyses of competition for food in crayfish are tenuous, evidence to date has been negative and does not support a "food competition" hypothesis.

Habitat selection - In allopatry, adult $O$. rusticus preferred pools, whereas $O$. sanborni preferred banks and, to a lesser extent, pools (Fig. 2). The greatest number of adults of both species were found in pools. In sympatry, O. rusticus continued to occupy pools, though streambanks were used more than in allopatry. Orconectes sanborni used streambanks more often in sympatry than in allopatry $(P<0.01$, chi-square test of allopatric versus sympatric distributions). An increase in the species segregation in sympatry was clear; O. rusticus occupied pools whereas $O$. sanborni used banks almost exclusively (Fig. 2). 
A decrease in $O$. sanborni's use of pools in sympatry suggests avoidance of $O$. rusticus, an alteration in habitat suitability, or both. Percent cover, mean cover size, and water depth in pools did not differ in allopatry versus sympatry ( $P>0.05$, ANOVA). Although this was not a comprehensive documentation of habitat similarity, allopatric and sympatric sites appear similar enough to rule out the possibility that $O$. sanborni decreased their use of pools in response to habitat changes. It is unlikely that small changes in $O$. sanborni's sympatric habitat use could evoke the rapid replacement of the species, though such changes might influence mating efficiency or vulnerability to predation.

Orconectes rusticus and O. sanborni YOY selected streambanks in allopatry and sympatry (Fig. 2). Orconectes sanborni also occupied riffles in sympatry, a change from the allopatric condition. Percent cover, mean cover size, and water depth in riffles all were higher at the sympatric site than at either allopatric site $(P=0.01,0.02$, and 0.03 , respectively). Deep

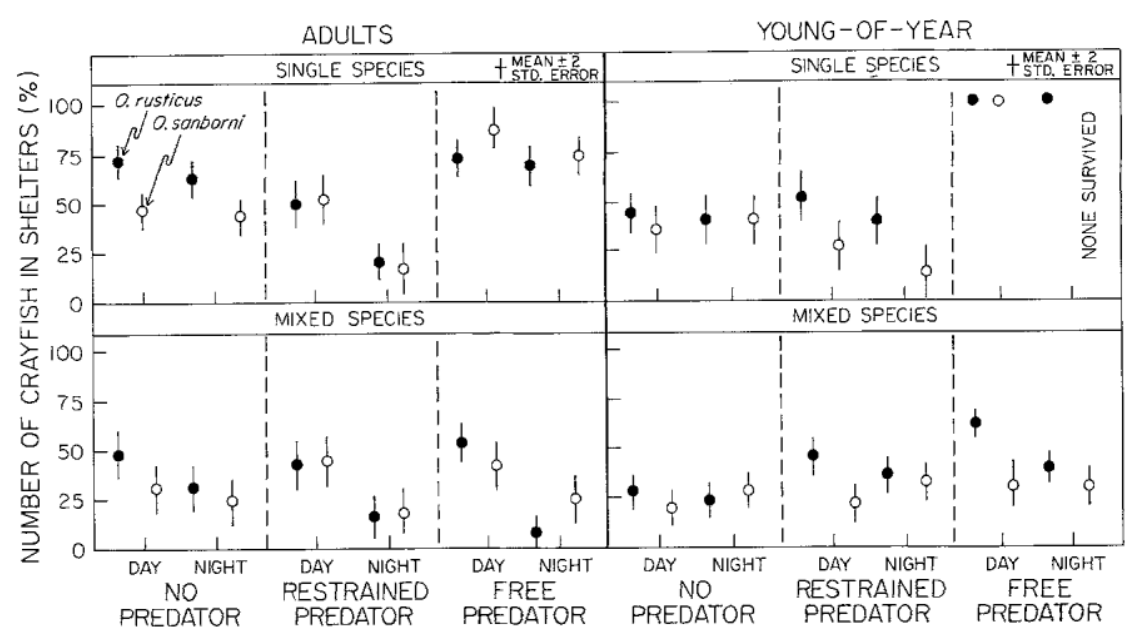

Fig. 3. Adult and young-of-year shelter use for $O$. rusticus and $O$. sanborni in laboratory experiments with three predator treatments. Means and standard errors were based on nine day and six night observations on four crayfish per aquarium across eight aquaria

riffles, with large abundant cover are probably suitable habitat for YOY crayfish, and thus might explain $O$. sanborni's increased use of riffles. If riffles were more suitable habitat in the sympatric area than in the allopatric areas, both $O$. rusticus and $O$. sanborni should have used riffles more; $O$. rusticus did not. This finding suggests that $O$. sanborni's increased use of riffles in sympatry resulted from factors other than changes in habitat suitability or that $O$. sanborni was more sensitive to habitat differences than was $O$. rusticus. It is unlikely that $O$. sanborni moved to riffles to avoid YOY $O$. rusticus, because YOY are not aggressive. Greater predation on $O$. sanborni YOY might have decreased their numbers in pools and streambanks (where predators are more abundant) or induced an escape response to riffles, where predator density is low. Differential susceptiblity to predation is examined in the next section.

Shelter use and predation susceptability - Crayfish shelter use was similar across treatments (Fig. 3), though $O$. rusticus initially sought shelter more frequently than did $O$. sanborni $m$ the single-species, no-predator treatment $(P=0.01)$. In the single-species 
experiments, $O$. rusticus's shelter use at night declined $(P<0.01)$ when a restrained predator was added, then increased $(P<0.01)$ when the predator was freed. Shelter use in the initial nopredator treatment was probably elevated because of handling stress and acclimation to experiment tanks. Orconectes sanborni adults increased both day and night shelter use when the predator was free $(P<0.01, P=0.04$, respectively). Thus, both species were capable of distinguishing real predatory threats (i.e., free bass) from false ones (i.e., restrained bass). Observations made during experiments confirmed that crayfish initially responded to movements by restrained bass by remaining motionless, but quickly adjusted to predator presence and resumed movement. Free bass were unable to feed on adult crayfish because of the large size of the crayfish. Crayfish responded to bass feeding attempts by displaying with raised chelae and seeking shelter.

Shelter use in the mixed-species experiment was lower than in the single-species experiment, presumably because overall shelter availability was lower (Fig. 3). Because species were of equal size in the experiment, neither species was dominant; hence neither species could sequester a disproportionate number of shelters. The presence of a predator in the mixed-species experiments did not influence shelter use (Fig. 3). Bass again attempted to eat crayfish, but typically were attacked by at least one and often several crayfish. Because shelters were scarce and crayfish numerous, interactions between animals were frequent. Crayfish appeared to respond more to each other than to bass, orienting towards the bass only when bass approached within $10 \mathrm{~cm}$. In the field $O$. rusticus are larger, therefore dominant over $O$. sanborni, and should win more interspecific confrontations for shelter. If large predators were present and shelter limiting, these interactions might result in higher mortality for $O$. sanborni. Extensive seining at all three field sites produced no large fish predators. Hence, differential predation by fishes on adult crayfish cannot account for the replacement of $O$. sanborni by $O$. rusticus in the streams we examined. Adult crayfish may be prey to other vertebrates (e.g. snakes, turtles, raccoons), but no census of their numbers was taken.

In single-species experiments, more YOY crayfish occupied shelters in the free-predator treatment than in the other two predator treatments $(P<0.05$; Fig. 3). However, predation eliminated many individuals in that treatment, leaving only those initially in shelters. Thus, increased shelter use in the free-predator treatment was an artifact of predation, not a response to it. In the mixed-species experiment, shelter use by $O$. rusticus increased gradually from the nopredator treatment through the free-predator treatment (Fig. 4). Orconectes rusticus typically occupied more shelters than $O$. sanborni in the single- and mixed-species experiments, significantly so during the day in the single-species restrained-predator treatment and the mixedspecies retrained- and free-predator treatments $(P<0.05$, all treatments). More YOY O. rusticus survived the predation experiments than $O$. sanborni (Fig. 5), presumably a consequence of $O$. rusticus's more frequent use of shelter. However, autecological differences between the species' susceptiblity to predation cannot lead to replacement, unless mortality of the native species increases in sympatric areas relative to allopatric areas. In the laboratory, both species survived better in the mixed-species treatment than in the single-species treatment, but corresponding field data are unavailable. Thus, the impact of differential predation on natural populations is unclear.

Medvick (1980) found that in laboratory aquaria YOY O. rusticus survived bass predation better than YOY O. virilis, but not YOY O. propinquus. Though shelter use per se was not monitored in her experiments, crayfish survived only in treatments where shelter was 


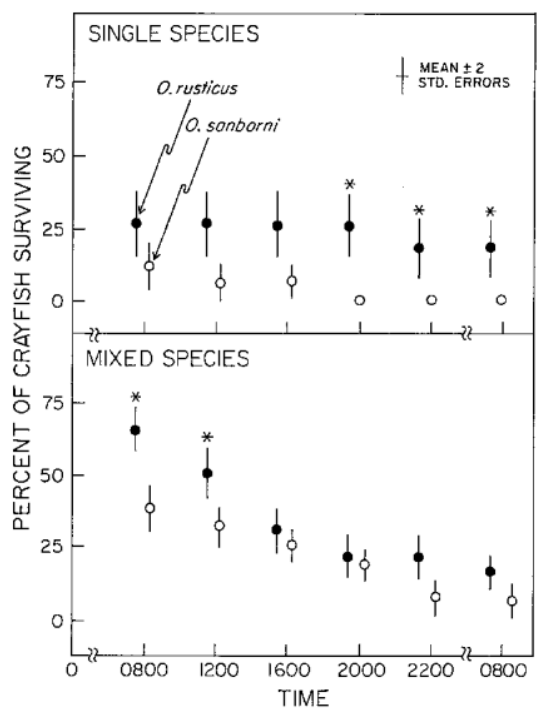

Fig. 4. Survival of young-of-year $O$. rusticus and $O$. sanborni in unrestrained-predator treatments in single- and mixed-species shelter-use experiments. Means and standard errors are based on 8 replicates per experiment. Each observation was based on 4 or 8 crayfish per tank in single- and mixed-species experiments, respectively. Differences $(P<0.05$, chi-square contingency Table) between the numbers of each species surviving at a particular time are indicated by a star $(\star)$
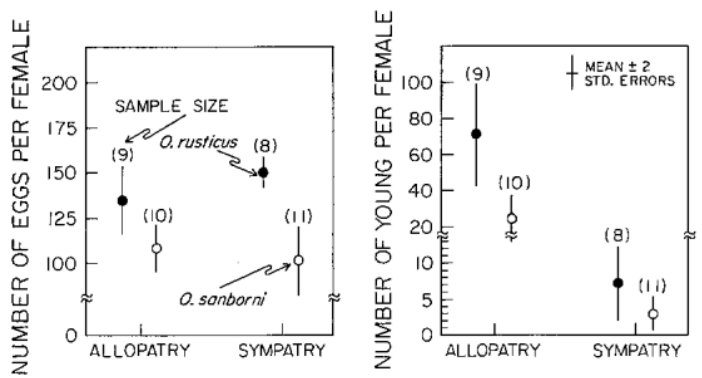

Fig. 5. The number of eggs and young produced per female of O. rusticus and O. sanborni in allopatric and sympatric sites in North Fork Creek, Licking County, Ohio

provided. She concluded that $O$. rusticus YOY avoided predation by being larger and thus more aggressive in acquiring shelter. Our documentation of shelter use and its influence on survival of YOY support the hypothesis generated by Medvick (1980). If size governs the procurement of shelter, as Medvick (1980) suggested, then larger species (e.g. O. rusticus) should experience lower predator-induced mortalities. If predators are sufficiently abundant and shelter in short supply, differential susceptibility to predation of YOY, favoring O. rusticus, could contribute to the replacement of $O$. sanborni.

Mate selection - Male $O$. rusticus mated primarily with female $O$. rusticus $(92 \%$ of the matings involving male $O$. rusticus; $\mathrm{n}=26$ mating pairs), whereas male $O$. sanborni mated with female $O$. sanborni only occasionally ( $28 \%$ of the matings involving male $O$. sanborni; $n=36$ 
mating pairs). Orconectes sanborni males actually preferred O. rusticus females (27\% of matings) to those of their own species. In fact, $O$. sanborni males mated just as often with $O$. rusticus females as $O$. rusticus males did. Tested against the null hypothesis of random mating (i.e., equal probability of mating with $O$. rusticus as $O$. sanborni females), males of both species were highly selective $(P<0.02$, chi-square goodness of fit test).

Using the same experimental design with O. rusticus and O. propinquus, Tierney and Dunham (1983) found that $O$. rusticus and O. propinquus males chose O. rusticus females as mates. Their results with $O$. rusticus and $O$. propinquus parallel ours with $O$. rusticus and $O$. sanborni. Capelli and McIntire's (1983) mate-selection results contradict those of Tierney and Dunhum and ours. They found that $O$. rusticus males mated interspecifically more often than $O$. propinquus males (45\% versus 24\%). Sex ratios in Capelli and McIntire's experiments were skewed in favor of males 2:1, whereas in Tierney and Dunham's and our experiment sex ratios were 1:1, approximating field sex ratios. The rationale for altering natural sex ratios in favor of males is not obvious. Capelli and McIntire (1983) apparently did so to keep crayfish densities comparable with those in other experiments they were performing. Because we used natural field densities and sex ratios, we believe our results and those of Tierney and Dunham are probably more indicative of mate selection than those of Capelli and Mclntire (1983).

In other experiments, Tierney and Dunham (1982) evaluated chemical cues as a means of mate discrimination in naturally coexisting and non-coexisting species. They concluded that coexisting pairs $(O$. propinquus and $O$. virilis) could chemically distinguish their mates from their congeners' mates, but non-coexisting pairs (O. rusticus and O. propinquus or O. rusticus and $O$. virlis) could not. However, our mate selection results, as well as Tierney and Dunham's, show that despite the inability of $O$. rusticus to distinguish chemically between species, they did preferentially select females of their own species as mates. Orconectes sanborni males did not select females of their species, preferring instead $O$. rusticus females. Apparently, a secondary mechanism operates that enables $O$. rusticus, but not $O$. sanborni, to acquire appropriate mates.

Crayfish mate size assortively; females are typically 1-2 mm CL smaller than males (Prins 1968; Stein and Magnuson 1976). This relationship is maintained through a precopulatory sequence where male crayfish attack and attempt to subdue females. Males typically use little discretion in choosing mates, frequently copulating with other males (Mason 1970; Pippett 1977; Capelli 1982). Females actively resist all mating attempts and are equally unreceptive to advances by males of any size or species (Tierney and Dunham 1983). Thus, aggressive responses of females to potential mates may operate as a size-selective mechanism in conjunction with a chemically controlled species-isolating mechanism (Itagaki and Thorp 1981; Berrill and Arsenault 1982). Because crayfish mate size assortively, O. rusticus and $O$. sanborni males should select the largest available females, which in sympatry are O. rusticus females. Similarities in the species' mating behavior coupled with ineffective chemical isolating mechanisms may explain sympatric mate selection anomalies.

In a similar situation with three parapatric species of ticks, short-range pheromone interference led to increased interspecific copulation, which in turn reduced fecundity of all three species in sympatry (Andrews et al. 1982). The ramifications of crayfish mate selection anomalies are discussed in the next section.

Reproductive success - More $O$. rusticus females than $O$. sanborni females were gravid in sympatry, whereas the reverse was true in allopatry $(O$. rusticus $=61 \%$ versus $O$. sanborni $=$ $39 \%$ and $O$. rusticus $=43 \%$ versus $O$. sanborni $=61 \%$ respectively; $P<0.01$, chi-square 
contingency table). Orconectes rusticus females produced more eggs ( $P<0.01$, t-test) and young $(P=0.02)$ in allopatry than $O$. sanborni females (Fig. 5). Similarly, in sympatry, O. rusticus produced more eggs per female than $O$. sanborni, but not more young $(P<0.01$ and $P>0.05$, respectively). Overall, the number of eggs per female for both species changed little from allopatry to sympatry, but the number of young decreased markedly for both.

Because numbers of young (as opposed to egg numbers) were reduced in sympatry, fertilization was probably impaired. Recall that crayfish extrude unfertilized eggs, attach them to their abdomens, and then fertilize them with stored sperm. Some evidence suggests that sperm is obtained from a number of matings during the mating season (Capelli 1975). As with other arthropods (Hotchkiss-Pruzan et al. 1981; Johnson 1982), multipaternity presumably results in higher female fecundity. If interspecific matings decrease fecundity or result in nonviable hybrid offspring, $O$. sanborni males could reduce the reproductive success of $O$. rusticus by preferentially mating with $O$. rusticus females. Orconectes sanborn's reproductive success also would decline as a result of fewer intraspecific matings.

In 1982, the consequence of these mating interactions was a $90 \%$ drop in recruitment for both species in sympatry as compared to allopatry. Decreases in recruitment of the same magnitude have been reported for other arthropods (Parker 1978; Hotchkiss-Pruzan et al. 1981; Andrews et al. 1982) but are not necessarily characteristic of a sympatric condition. Reproductive success in sympatry should fluctuate considerably with changes in population sizes and densities, sex ratios, and segregation. Yet, because O. rusticus consistently chooses appropriate mates, has proportionally more gravid females, and produces on average more young per female than $O$. sanborni, O. rusticus should persist at increasingly higher densities in sympatry than $O$. sanborni. This type of reproductive interference, characterized by rapid and often dramatic population reductions, probably contributes to the replacement of $O$. sanborni by O. rusticus.

\section{Conclusions}

Results from laboratory experiments and field analyses suggest that autecological differences, exacerbated by temporal overlap in life histories, are the primary mechanisms governing replacement of $O$. sanborni by $O$. rusticus. Most important are differences in the species' mate selection and recruitment, though differential susceptiblity of young-of-year to predation may also be important in areas where predators are abundant.

Distributions of several species of crayfish have been attributed to competitive exclusion (Penn and Fitzpatrick 1963; Aiken 1965; Bovbjerg 1970; Rorer and Capelli 1978; Capelli 1982), though evidence for competition in these studies is largely circumstantial and alternative hypotheses have not been explored. The replacement of $O$. sanborni in Ohio does not appear to be a consequence of competitive exclusion. No evidence of interference or exploitative competition for food or habitat was found. Though interspecific encounters between crayfish were invariably frequent in sympatry, they did not result in reduced food consumption or habitat partitioning. In contrast, similarities in $O$. rusticus's and $O$. sanborn's mate selection systems resulted in reduced reproductive success for both species in sympatry. Because $O$. rusticus produces more young than $O$. sanborni and O. rusticus young are faster growing, O. rusticus maintains higher population growth, perhaps enabling the species to recover from population reductions more rapidly than $O$. sanborni. When these factors are coupled with the deleterious consequences of aggressive subordinance and greater susceptiblity to predators, $O$. sanborni 
populations are clearly at a disadvantage when interacting with populations of $O$. rusticus. Thus, if population growth rates of $O$. sanborni are insufficient to offset population reductions due to the synergistic effects of $O$. rusticus's presence and density-dependent and -independent regulatory processes, $O$. sanborni will be driven locally extinct.

\section{Acknowledgments}

P. Chesson, B. Felgenhauer, H.H. Hobbs III, J. Margraf, R. Lipcius, and A.J. Tierney provided critical reviews of the manuscript. Discussions with T. Berner, G. Capelli, J. Downhower, L. Fairchild, G. Mittlebach, E. Rankin, and members of the Ohio State University Aquatic Ecology Group resulted in stimulating and constructive review of the experiments and ideas presented here. Several people assisted in the laboratory and field; in particular we wish to thank M. Curtis, T. Crowl, J. Lamia, and V. Murchake. Sincere thanks are extended to J. Drier for the many hours spend drafting and revising figures and to A. Thistle for preparing the manuscript. The Ohio Cooperative Fishery Research Unit supplied valuable logistic support. Funding for the project was provided by the Ohio Department of Natural Resources - Division of Natural Areas and Preserves, a Sigma Xi Grant-in-aid of Research, and an Ohio State University Grant-in-aid of Research.

\section{References}

Aiken DE (1965) Distribution and ecology of three species of crayfish from New Hampshire. Amer Midi Nat 73:240-244

Andrews RH, Petney TN, Bull CM (1982) Reproductive interference between three parapatric species of reptile tick. Oecologia (Berlin) 52:281-286

Berglund A (1982) Coexistence, size overlap, and population regulation in tidal vs. non-tidal Palaemon prawns. Oecologia 54:1-7

Berrill M (1978) Distribution and ecology of crayfish in the Kawartha Lakes region of southern Ontario. Can J Zool 56:166-177

Berrill M, Arsenault M (1982) Spring breeding of a northern temperate crayfish, Orconectes rusticus. Can J Zool 60:2641-2645

Bertness M (1981) Competitive dynamics of a tropical hermit crab assemblage. Ecology 62:751-761

Bouchard RW (1978) Taxonomy, distribution and general ecology of the genera of North American crayfishes. Fisheries 3:11-16

Bovbjerg RV (1953) Dominance order in the crayfish Orconectes virilis (Hagen). Physiol Zool 26:173-178

Bovbjerg RV (1970) Ecological isolation and competitive exclusion in two crayfish (Orconectes virlis and Orconectes immunis). Ecology 51:225-236

Brown K (1981) Low genetic variability and high similarities in the crayfish genera Cambarus and Procambarus. Amer Midi Nat 105:225-232

Butler MJ IV (1983) An analysis of replacement mechanisms governing range expansion in crayfish. MS Thesis, The Ohio State Univ, Columbus, Ohio

Caine EA (1978) Comparative ecology of epigean and hypogean crayfish (Crustacea: Cambaridae) from northwestern Florida. Amer Midi Nat 99:315-329

Capelli GM (1975) Distribution, life history, and ecology of crayfish in northern Wisconsin, with emphasis on Orconectes propinquus (Girard). Ph D Dissertation, Univ of Wisconsin-Madison

Capelli GM (1982) Displacement of northern Wisconsin crayfish by Orconectes rusticus (Girard). Limnol Oceanogr 27:741-745

Capelli GM, Capelli JF (1980) Hybridization between crayfish of the genus Orconectes: morphological evidence (Decapoda: Cambaridae). Crustaceana 39:121-132

Capelli GM, Hamilton PA (1984) Effects of food, shelter, and time of day on aggressive activity in the crayfish Orconectes rusticus (Girard). J Crustacean Biol 4:252-260

Capelli GM, Magnuson JJ (1983) Morphoedaphic and biogeographic analysis of crayfish distributions in Northern Wisconsin. J Crustacean Biol 3:548-564

Capelli GM, Mclntire PE (1983) Mating duration, sperm plug formation, and mating among crayfish of the genus Orconectes (unpublished)

Capelli GM, Munjal BL (1983) Aggressive interactions and resource competition in relation to species displacement among crayfish of the genus Orconectes. J Crustacean Biol 2:486-492 
Caswell H (1978) Predator-mediated coexistence: a nonequilibrium model. Amer Natur 112:127-154

Chesson PL, Warner RR (1981) Environmental variability promotes coexistence in lottery competitive systems. Amer Natur 117:923-943

Commins HN, Hassell MP (1976) Predation in multi-prey communities. J Theor Biol 62:93-114

Connell JH (1980) Diversity and coevolution of competitors, or the ghost of competition past. Oikos 35:131-138

Connor EF, Simberloff D (1979) The assembly of species communities: Chance or competition? Ecology 60:11321140

Courtenay WR (1978) The introductions of exotic organisms. In Brokaw HP (ed) Wildlife and America. US Govt Printing Office, Washington, DC

Courtenay WR Jr, Robins CR (1973) Exotic organisms: an unsolved, complex problem. Bio Science 25:306-313

Diamond JM (1978) Niche shifts and the rediscovery of interspecific competition. Amer Sci 66:322-331

Fielder DD (1972) Some aspects of the life histories of three closely related crayfish species Orconectes obscurus, O. sanborni, and $O$. propinquus. Ohio J Sci 72:129-145

Frank WJ (1983) Habitat preference from usage-availability data. J Wildl Biol (submitted)

Freeland WJ (1983) Parasites and the coexistence of animal host species. Amer Natur 121:223-236

Glasser JW (1982) On the causes of temporal change in communities: modification of the biotic environment. Amer Natur 110:375-390

Grossman GD (1980) Food, fights, and burrows: the adaptive significance of intraspecific aggression in the Bay Goby (Pisces: Gobiidae). Oecologia (Berlin) 45:261-266

Hazlett BA, Rittschoff D, Ameyaw-Akumfi C (1979) Factors affecting the daily movements of the crayfish Orconectes virilis (Hagen 1870) (Decapoda: Cambaridae). Crustaceana suppl 5.

Heckenlively DB (1970) Intensity of aggression in the crayfish Orconectes virilis (Hagen). Nature 225:180-181

Hixon MA (1980) Competitive interactions betwen California reef fishes of the genus Embiotoca. Ecology 61:918931

Hotchkiss-Pruzan A, DeJaiane D, Faro S (1981) Sperm utilization in once- and twice-mated Drosophila pseudoobscura females. Amer Natur 118:37-45

Itagaki H, Thorp JH (1981) Laboratory experiments to determine if crayfish can communicate chemically in a flowthrough system. J Chem Ecology 7:115-126

Jezernac RF (1967) A distribution of crayfishes (Decapoda: Astacidae) of the Chagrin River, in northeastern Ohio. MS Thesis, The Ohio State Univ, Columbus, Ohio

Johnson C (1982) Multiple insemination and sperm storage in the isopod, Venezillo evergladensis Schultz, 1963, Crustaceana 42:225-232

Larson RJ (1980) Competition, habitat selection, and the bathymetric segregation of two rockfish (Sebastes) species. Ecol Monogr 50:221-239

Laycock G (1966) The alien animals. Nat Hist Press, Am Mus Nat Hist, Garden City, New York

Lorman JG (1975) Feeding activity of the crayfish Orconectes rusticus in a northern Wisconsin Lake. MS Thesis, Univ of Wisconsin, Madison, Wisc

Lorman JG (1980) Ecology of the crayfish Orconectes rusticus in northern Wisconsin. PhD Dissertation, Univ of Wisconsin, Madison, Wise

Lorman JG, Magnuson JJ (1978) The role of crayfishes in aquatic systems. Fisheries 3:8-11

Mason JC (1970) Copulatory behavior of the crayfish Pacifasticus trowbrigii (Stimpson). Can J Zool 48:969-976

Medvick P (1980) Aggressive interactons and predation avoidance in young-of-the-year of three species of crayfish (Orconectes) (unpublished manuscript).

Merkle EL (1969) Home range of crayfish Orconectes juvenalis. Amer Midi Nat 81:228-235

Momot WT, Gowing H (1972) Differential seasonal migration of the crayfish Orconectes virilis (Hagen) in marl lakes. Ecology 53:479-483

Momot WT, Gowing H, Jones P (1978) The dynamics of crayfish and their role in ecosystems. Amer Midi Nat 99:10-35

Munjal BM (1980) Aggressive interactions, shelter competition, and mating preference as potential mechanisms relating to species displacement among crayfish of the genus Orconectes. MS Thesis, William and Mary Univ, Williamsburg, Va

Parker GA (1978) Searching for mates, pp 214-245 in Krebs JR, Davis NB (eds) Behavioral Ecology: An Evolutionary Approach. Blackwell Scientific Pub., Oxford, England

Parsons PA (1982) Adaptive strategies of colonizing animal species. Biol Rev 57:117-148

Penn HG, Fitzpatrick JF Jr (1963) Interspecific competition between two sympatric species of dwarf crawfishes. Ecology 44:793-797 
Pianka ER (1976) Competition and niche theory, pp 114-141 in May RM (ed) Theoretical Ecology: Principles and Applications. Saunders WB, Philadelphia

Pipett MR (1977) Mating behavior of the crayfish Orconectes nais (Faxon) (Decapoda: Astacidea). Crustaceana 32:265-271

Prins R (1968) Comparative ecology of the crayfishes Orconectes rusticus and Cambarus tenebrosus in Doe Run, Meade County, Kentucky. Int Rev Gesamten Hydrobiol 53:667-714

Rorer WE, Capelli GM (1978) Competitive interaction between two Mountain Lake crayfish species, with life history notes. Virginia J Sci 29:245-248

Schwartz FJ, Rubelmann R, Allison J (1963) Ecological population expansion of the introduced crayfish, Orconectes virilis. Ohio J Sci 63:266-273

Smith DG (1979 a) New locality records of crayfishes from the middle Hudson River system. Ohio J Sci 79:133-135

Smith DG (1979 b) Variability of crayfish of the virilis section (Cambaridae: Orconectes) introduced into New England and eastern New York. Amer Midi Nat 102:388-391

Smith DG (1981 a) Evidence for hybridization between two crayfish species (Decapoda: Cambaridae: Orconectes) with a comment on the phenomenon in Cambarid crayfish. Amer Midi Nat 120:405-407

Smith DG (1981b) A note on the morphological variability of Orconectes kinderhookensis (Decapoda: Cambaridae) from the Hudson River system in New York. J Crustacena Biol 1:389-391

Smith BR, Tibbies JJ (1980) Sea lamprey (Pertomyzon marinus) in lakes Huron, Michigan, and Superior: History of an invasion and control 1936-1978. Can J Fish Aquat Sci 37:1780-1801

Stein RA (1975) Sexual dimorphism in crayfish chelae: functional significance linked to reproductive activities. Can J Zool 54:220-227

Stein RA (1977) Selective predation, optimal foraging and predatorprey interaction between fish and crayfish. Ecology 58:1237-1253

Stein RA, Magnuson J (1976) Behavioral response of crayfish to a fish predator. Ecology 57:751-761

St. John F (1970) The life history and reproduction of the crayfish Orconectes sanborni (Faxon) (Crustaceana: Decapoda: Astacidae). MS Thesis, The Ohio State Univ, Columbus Ohio

Tierney AJ, Dunham DW (1982) Chemical communication in the reproductive isolation of the crayfishes Orconectes propinquus and Orconectes virilis (Decapoda, Cambaridae). J Crustacean Biol 2:544-548

Tierney AJ, Dunham DW (1983) Behavioral mechanisms of reproductive isolation in crayfishes of the genus Orconectes. Amer Midi Nat (in press)

Tilman D (1982) Resource Competition and Community Structure. Princeton University Press, 296 pp Turner C (1926) The Crayfishes of Ohio. Ohio Biol Survey Bull 13(3)

Werner EE (1977) Species packing and niche complementarity in three sunfishes. Amer Natur 111: 553-578

Wiens JA (1977) On competition and variable environments. Amer Sci 65:590-597 Zaret TM, Paine RT (1973) Species introduction in a tropical lake. Science 182:449-55 